\title{
Attributes that come to mind in the TOT state
}

\author{
EUGENE LOVELACE \\ Alfred University, Alfred, New York
}

\begin{abstract}
This study explored the sorts of attributes that college students were able to report when in the tip-of-the-tongue (TOT) state. Forty-five questions were posed; the answers sought were mostly names of famous people or characters in famous literary works. When students believed an answer they provided was wrong but believed that they would recognize the to-be-recalled item if they saw it, they were asked to provide any information they could about the answer. They then received a four-alternative, forced-choice recognition test. In addition to such structural attributes as word length, letters in the target name, and phonemic features, the students often reported frequency of occurrence of the word and such semantic attributes as country or language associated with the name, descriptive attributes, and context or situational attributes. The TOT states were predictive of superior recognition, but the number and types of attributes reported did not appear to be systematically related to recognition success.
\end{abstract}

One of the earliest forms of metamemory to be systematically studied involved the ability of individuals to monitor whether or not they would recognize an item they could not recall at the moment (Hart, 1965, 1967). Hart found that the ability of individuals to monitor what was available in memory, even when currently inaccessible, was substantially greater than chance. He referred to this as "feeling-of-knowing" (FOK), and it has since received considerable attention (see Nelson, 1984, for a recent review).

The early literature concerning the "tip-of-the-tongue" (TOT) state was separate and distinct from the literature on FOK, yet TOT is clearly another such memory monitoring with underlying process akin to that of FOK. In the initial paradigm for inducing the TOT state in the laboratory, Brown and McNeill (1966) presented students with the dictionary definitions of low-frequency words and asked them to try to recall the words. On some occasions a student was unable to write down the word but felt that it was on the tip of the tongue. On those occasions Brown and McNeill asked the student to attempt to provide certain attributes of the unrecallable item. These attributes were primarily structural and phonemic (e.g., the number of syllables in the word, the initial letter of the word, words that were similar in sound).

It has been suggested that the subjective strength of the FOK or the TOT state hinges on the number or proportion of the attributes of the to-be-recalled item that the person can retrieve (e.g., Blake, 1973; Brown \& McNeill, 1966; Schacter \& Worling, 1985; Yarmey, 1973). According to this view, one has the FOK because of the abil-

The author wishes to thank J. D. Savage for assistance throughout this study and R. Galford, R. Lieser, J. Parker, and R. Sienkiewicz for assistance in judging categories of response. The author acknowledges, with appreciation, the comments of D. Meissner, N. Furlong, and R. Maiden on a draft of this paper. The author's current address is Psychology Division, Science Center, Alfred University, Alfred, NY 14802. ity to retrieve some of the constellation of attributes that constitute that item in memory (cf. Underwood, 1983). Since it may well be this same process that underlies both the FOK and the TOT states, they will hereafter be collectively referred to in this article as TOT.

The present research was designed to explore the kinds of attributes that spontaneously occur to the individual in the TOT state. Although Brown and McNeill (1966) provided evidence that certain attributes of unrecalled words were likely to be known, their procedure involved requesting information about those attributes that they chose on the basis of their own introspections. In the present study, the individual in the TOT state was asked for any information he/she could provide about the tobe-recalled word, but no prior judgment was made about the sorts of attributes the person should or might provide.

\section{METHOD}

\section{Subjects}

Twenty-one students from an introductory psychology class at the University of Virginia received extra course credit for participating in this study.

\section{Procedure}

In the initial phase of the study, each student was presented with 45 questions, each question written on a $3 \times 5$ card. The questions were from a variety of areas: literature, history, science, and humanities. Most required the recall of a name: a character in a literary work, the author/artist or title of a work, or a famous scientist or politician. All were judged to deal with material to which a college student might have been exposed during his/her formal education. Most questions called for a single-word response; a few had two- or three-word answers (e.g., Ichabod Crane, Helen of Troy). Students were told that for many of the questions they probably would not know the answers, but they were instructed to guess whenever possible ("strongly urged to ... answer with your best guess"). After writing the answer to each question, they were to make two judgments about the response they had provided: first they indicated whether they believed their response was correct or incorrect, and second they indicated whether they thought they would recognize the correct answer to the question if they saw it. For the latter they responded on a 4-point scale, verbally anchored as I'm sure I 
would not, I don't think I would, I probably would, or I'm sure I would recognize the item. Whenever the pattern of responses was such that the student felt his/her response was not correct, but that he/she could recognize the correct response, the student was asked to give additional information. The instruction for this part of the task read:

Often when a person cannot bring a certain word to mind, he can nevertheless produce things about the word itself. Perhaps you can tell me certain things about this word that you are looking for, or perhaps you can tell me something that the missing word reminds you of. Please tell me whatever you can about the word for which you are searching. Do not be inhibited because you feel that some point may be insignificant or silly. I would like to know whatever you can tell me about the missing word and any feelings you may have about the word.

The student's comments were tape-recorded to facilitate scoring of the sorts of attributes each individual produced in response to any question that had induced the TOT state.

After all questions were presented in Phase 1, the questions were presented again, in the same order, as a four-alternative forced-choice recognition test. Both phases of the task were self-paced.

\section{RESULTS}

\section{TOT Frequency and Accuracy}

The number of questions producing the TOT state (where the student reported an answer that he/she correctly believed was wrong and yet indicated a belief that he/she would recognize the correct answer) ranged from 3 to 16 , with a mean of $9.4(S D=3.9)$. This represented about $21 \%$ of the questions. The proportion of correct selections in the four-alternative forced-choice task for these TOT items was .71, whereas the proportion of correct selections for those items that were wrong and were judged not to be recognizable was . 37 . This confirms the usual memory monitoring finding: recognition of items judged to be in the TOT state was clearly superior to random selection (.25) and to recognition of items not in the TOT state.

\section{Analyzing Attributes Reported}

My primary research assistant (J. D. Savage) and I began the analysis by attempting to characterize the sorts of attributes present in the comments of students when in the TOT state. We felt that the vast majority of these comments could be assigned to the following attribute categories: (1) word length, as an observation about the whole word or about the number of syllables; (2) letters contained in the word, sometimes with specification of these as letters at the beginning or at the end of the word; (3) sound properties, of the whole word or of the beginning or ending; (4) frequency of occurrence of the word; (5) geographic location or country or language of origin (e.g., "a French name," "an English painter," "a Spanish word"); (6) an era or point in time with which the word was associated (e.g., " an ancient Greek," "in the suffragette era," "an old, maybe Biblical name"'); (7) a descriptive word that seemed to point to a particular characteristic attribute of the item (e.g., " a spidery person," "a hick name," "a bizarre name, something to do
Table 1

Categories of Attributes Reported, Proportion of All

Scorings of Comments Containing Each Attribute, and Mean Frequency and Standard Deviation

With Which Each of Five Judges Scored the Occurrence of Each Attribute

\begin{tabular}{lccc}
\hline \multicolumn{1}{c}{$\begin{array}{c}\text { Category of } \\
\text { Attributes }\end{array}$} & $\begin{array}{c}\text { Proportion of } \\
\text { All Scorings* }\end{array}$ & $\begin{array}{c}\text { Mean } \\
\text { Frequency }\end{array}$ & $\begin{array}{c}\text { Standard } \\
\text { Deviation }\end{array}$ \\
\hline Word Length & .14 & 28.4 & 3.0 \\
Number of Syllables & .17 & 34.0 & 3.1 \\
Beginning Letter & .12 & 23.0 & 2.1 \\
Ending Letter & .02 & 3.2 & 0.8 \\
Letter Contained & .08 & 16.4 & 1.9 \\
Beginning Sound & .02 & 3.6 & 2.0 \\
Ending Sound & .02 & 3.8 & 4.6 \\
Sound of Whole Word & .07 & 14.0 & 9.7 \\
Frequency of Occurrence & .11 & 27.0 & 2.1 \\
Country, Language & .14 & 28.2 & 2.2 \\
Time (Era) & .03 & 5.6 & 3.9 \\
Descriptive Attribute & .20 & 40.4 & 6.2 \\
Context (Coordinate) & .32 & 62.6 & 20.5 \\
Partially Correct & .04 & 8.4 & 5.4 \\
\hline
\end{tabular}

*These proportions do not total 1.00 since each TOT state scored produced 2.65 attributes on average.

with jumpy," "a bouncy name"); (8) a contextual or situational association, which was most often something from the story line or other works of the artist/author, or names of other artists who belonged to the same "school"; (9) occasions on which they were able to give a response that was partially correct; and (10) miscellaneous responses that we could not fit into any of the above categories.

With these categories in mind, five judges examined the tapes and recorded the occurrences of these categories wherever the judges felt they existed in the responses of the students while in the TOT state. The first column of Table 1 shows the categories, and the second column shows the proportion of all scorings of TOT states (all 198 states times 5 judges) that were judged to fit into each category. In Table 1, it can be seen that in nearly one third of the cases the length of the sought item was mentioned; the combined occurrences for word length and number of syllables is about $31 \%$. Comments about letters in the sought item occurred in about $22 \%$ of the TOT scorings; letters at the beginning of the word were the most frequently given, occurring nearly $12 \%$ of the time. About $11 \%$ of the comments included reference to the sound pattern of the word, most often to the sound of the whole word.

The percentages mentioned above represent the frequencies with which our subjects reported the sorts of attributes that Brown and McNeill (1966) requested of their participants. The participants in the present study also mentioned $11 \%$ of the time how common or uncommon the word sought was, about $14 \%$ of the time something about the country or language of origin of the word, $20 \%$ of the time a descriptive word or attribute, and about $32 \%$ of the time a context (situation or coordinate). The mean 
number of attributes scored per question, averaged over the five judges, was 2.65 .

The last two columns of Table 1 show the means and standard deviations of the frequencies with which the five judges reported each attribute. For the most part, these mean frequencies provide a picture that is very similar to that of the proportions of all scorings as shown in Column 2.

Placement of the students' remarks into categories was not simple and clearcut, and agreement among the five judges was not as high as one might like. The agreement among judges was highest for word and syllable length, for letter the word began with, for frequency of the word, and for country or language of origin. (Note the large means and small standard deviations for these attributes.) In all of these cases, at least four of the five judges were in agreement the majority of the time. Agreement was particularly poor in the scoring of sounds of the word and in scoring partially correct responses.

To explore whether attribute recall was related to strength of the TOT state, two correlation coefficients were calculated. Neither the average number of attributes reported per TOT state nor the number of different types of attributes reported was significantly related to the proportion of these items for which a correct selection was made in the recognition test $(r=.17$ and $r=.11$, respectively). In addition, when attributes were separated into those that were structural and those that were more semantic, neither the number of occurrences of either of these categories nor the ratio of structural to semantic attributes was significantly correlated with proportion correct for these items in the recognition test.

\section{DISCUSSION}

The present results confirm that the structural attributes Brown and McNeill (1966) requested from their subjects are among those that spontaneously occur to many individuals when in the TOT state. They also indicate that a number of semantically related attributes are given by subjects. Yarmey (1973) reported that, when given pictures of famous people to name, his subjects most often seemed to try first to think of the person's profession and then where they had seen the person; this demonstrates the priority of semantic and contextual attributes over structural ones. Although Yarmey asked the subjects specifically to report about these attributes, in the present study, in which the students had no constraints on the attributes they should report, the frequent reports of the semantic categories of context, descriptive attributes, and country/language seem analogous to the attributes given priority in Yarmey's study. The exact natures of these semantic features or associations are assumed to be dependent on the particular questions asked.

The validity of the target word the student had in mind while in the TOT state was not assessed in this study (cf. Koriat \& Lieblich, 1974); individuals sometimes had TOT states when they later indicated that the correctly recognized word was not their subjective target when they reported the TOT state. Thus, from the present study, one can describe only the types of attributes that occurred to these students while in the TOT state, not the relative predictive value of various types of attributes for accuracy in the recognition judgments. Schacter and Worling (1985) reported that subjects often made positive feeling-of-knowing judgments when they felt that they knew attributes, even when the attributes were in fact inaccurate. This may, at least in part, account for the lack of any strong connection in the present study between the number and kind of attributes recalled and the level of recognition performance. Another uncontrolled factor is the individual differences in the criterion for reporting attributes. Despite an effort to minimize the criterion and to get each student to report anything that came to mind, it is very likely that some individuals were unwilling to do so. In view of the relatively low number of attributes reported per TOT state (2.65), perhaps only particularly salient attributes were reported.

\section{REFERENCES}

BlaKe, M. (1973). Prediction of recognition when recall fails: Exploring the feeling-of-knowing phenomenon. Journal of Verbal Learning \& Verbal Behavior, 12, 311-319.

Brown, R. W., \& MCNeill, D. (1966). The "tip of the tongue" phenomenon. Journal of Verbal Learning \& Verbal Behavior, 5, 325-337.

HART, J. T. (1965). Memory and the feeling-of-knowing experience. Journal of Educational Psychology, 56, 208-216.

HART, J. T. (1967). Memory and the memory-monitoring process. Journal of Verbal Learning \& Verbal Behavior, 6, 685-691.

KoRIAT, A., \& LIEBLICH, I. (1974). What does a person in a "TOT" state know that a person in a "don't know" state doesn't know. Memory \& Cognition, 2, 647-655.

Nelson, T. O. (1984). A comparison of current measures of the accuracy of feeling-of-knowing predictions. Psychological Bulletin, 95,109-133.

SCHACTER, D. L., \& WORLING, J. R. (1985). Attribute information and the feeling-of-knowing. Canadian Journal of Psychology, 39, 467-475.

UNDERWOOD, B. J. (1983). Attributes of memory. Glenview, IL: Scott, Foresman.

YARMEY, A. D. (1973). I recognize your face but I can't remember your name: Further evidence on the tip-of-the-tongue phenomenon. Memory \& Cognition, 1, 287-290.

(Manuscript received for publication March 30, 1987.) 